\author{
Military Technical College \\ Kobry El-Kobbah, \\ Cairo, Egypt.
}

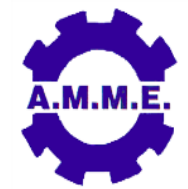
$18^{\text {th }}$ International Conference on Applied Mechanics and Mechanical Engineering.

\title{
EVALUATION OF ABRASIVE WATER JET MACHINING PROCESS PARAMETERS ON CUTTING HIGH STRENGTH HARD MATERIAL (ARMOX)
}

\author{
Y. M. Elattar ${ }^{1}$, H. A. Sonbol ${ }^{2}$ and M. A. Mahdy ${ }^{3}$
}

\begin{abstract}
This paper is dedicated to investigate the abrasive water-jet (AWJ) cutting parameters of hard-to-cut materials represented by Armox shielding steel plate of 7.6 $\mathrm{mm}$ thick. Experiments were carried out in machining Armox in order to investigate the possibility of using the AWJ process for machining process. Process variables such as water jet travers speed, water jet pressure, stand-off distance, and abrasive flow rate have been investigated to study the effect of each on the AWJ cutting process parameters. Cutting parameters such as the profiles of machined surfaces, kerf geometries and material removal rate were investigated.
\end{abstract}

The experimental results indicate that the traverse speed is a significant parameter on the surface roughness. It was also observed that the kerf taper ratio and surface roughness increase with increasing traverse speed in chosen conditions. Moreover, it shows that surface roughness, and the material removal rate are widely affected by the abrasive flow rate. The increase of abrasive flow rate yields the material removal rate but decreases the surface roughness. Stand-off distance and jet pressure almost had no effect on both surface roughness and material removal rate.

\section{KEYWORDS}

Abrasive water jet (AWJ), Armox, surface roughness, kerf geometry, material removal rate, MRR

1 Assist. Lecturer, Modern Academy for Engineering and Tech., Cairo, Egypt.

2 Professor, Design and Prod. Eng. Dpt., Ain Shams University, Cairo, Egypt.

3 Dean of Higher Institute for Engineering and Modern Technology Marg, Egypt. 


\section{NOMENCLATURE}

$\begin{array}{ll}\text { AWJ } & \text { Abrasive water jet } \\ \text { IDR } & \text { Initial Damage Region } \\ \mathrm{m}_{\mathrm{a}} & \text { Abrasive flow rate }(\mathrm{g} / \mathrm{min}) \\ \mathrm{R}_{\mathrm{a}} & \text { Surface roughness }(\mu \mathrm{m}) \\ \mathrm{RCR} & \text { Rough Cutting Region } \\ \mathrm{s} & \text { Stand-off distance }(\mathrm{mm}) \\ \mathrm{SCR} & \text { Smooth Cutting Region } \\ \mathrm{t} & \text { Thickness of tested specimen } \\ \mathrm{W}_{\mathrm{b}} & \text { Kerf width at bottom surface of specimen } \\ \mathrm{W}_{\mathrm{t}} & \text { Kerf width at top surface of specimen } \\ \theta & \text { kerf taper angle (rad) }\end{array}$

\section{INTRODUCTION}

ARMOX is protection steel used in military applications and armored shields. it is commonly used for security patrol vehicles, cash in transit vehicles, military armored vehicles, and in some protected facilities buildings. It has high strength, hardness and good toughness. It acquires these specific properties due to its chemical composition and a specific production process, finalized by very rapid quenching and tempering. The chemical purity in combination with very rapid cooling brings good toughness of material despite of tempering at very low temperatures. Due to these production process specifics, the producer recommends do not exceed the temperature about $200^{\circ} \mathrm{C}$ during the machining process [1-3].

Abrasive waterjet machining (AWJ) technology is one of the most recent nontraditional methods used in the industry for material processing with the distinct advantages of no thermal distortion, high machining versatility, high flexibility and small cutting forces. Since there is not any electrical or thermal energy used in this process, many material defects can be ignored. Compared with traditional and nontraditional machining technologies, AWJ machining has been used increasingly with extensive applications for the shape cutting of difficult-to-machine materials. Besides, the process is more economical and the material removal rate (MRR) is higher than those of non-traditional machining processes. In AWJ the material is removed by impact erosion of high pressure high velocity of water and entrained high velocity of grit abrasives on a workpiece. The slurry of particles and water is used as the cutting tool. There are many process parameters affect quality of machined surface cut by AWJ. Main process parameters are traverse speed, waterjet pressure, stand-off distance, and abrasive flow rate. Main quality parameters in AWJ are Surface Roughness $\left(\mathrm{R}_{\mathrm{a}}\right)$, Kerf width, and tapering of Kerf [4-7].

The aim of this study is to investigate experimentally the profiles of machined surfaces, kerf geometries and microstructural features of the machined surfaces in terms of traverse speed in AWJ machined Armox.

\section{EXPERIMENTAL WORK}

The material used in this study was Armox with a thickness of $7.6 \mathrm{~mm}$. The nominal 
chemical compositions of the test material are listed in Table 1 and the mechanical properties are shown in Table 2. The experiments were performed on a SOITAAB AWJ machine, Table 3 shows the machine specifications.

Table 1. Chemical composition of ARMOX [8].

\begin{tabular}{lllllllll}
\hline $\begin{array}{l}\mathrm{C} \\
(\max \%)\end{array}$ & $\begin{array}{l}\mathrm{Si} \\
(\max \%)\end{array}$ & $\begin{array}{l}\mathrm{Mn} \\
(\max \%)\end{array}$ & $\begin{array}{l}\mathrm{P} \\
(\max \%)\end{array}$ & $\begin{array}{l}\mathrm{S} \\
(\max \%)\end{array}$ & $\begin{array}{l}\mathrm{Cr} \\
(\max \%)\end{array}$ & $\begin{array}{l}\mathrm{Ni} \\
(\max \%)\end{array}$ & $\begin{array}{l}\text { Mo } \\
(\max \%)\end{array}$ & $\begin{array}{l}\mathrm{B} \\
(\max \%)\end{array}$ \\
\hline 0.32 & 0.4 & 1.2 & 0.010 & 0.003 & 1.0 & 1.8 & 0.7 & 0.005 \\
\hline
\end{tabular}

Table 2. Mechanical properties of ARMOX [8].

\begin{tabular}{lllllll}
\hline $\begin{array}{l}\text { Young's } \\
\text { modulus }\end{array}$ & $\begin{array}{l}\text { Poisson } \\
\text { coefficient }\end{array}$ & Density & $\begin{array}{l}\text { Yield } \\
\text { strength }\end{array}$ & $\begin{array}{l}\text { Tensile } \\
\text { strength }\end{array}$ & Elongation & Hardness \\
\hline 207 & 0.3 & 7850 & 1250 & $1450-1750$ & $8-10$ & $480-540$ \\
$(\mathrm{GPa})$ & & $\left(\mathrm{Kg} / \mathrm{m}^{3}\right)$ & $(\mathrm{MPa})$ & $(\mathrm{MPa})$ & $(\%)$ & $(\mathrm{HBW})$ \\
\hline
\end{tabular}

Table 3. General specifications of AWJ machine [9].

\begin{tabular}{l|l}
\hline Item & Identification \\
\hline Machine model & SOITAAB \\
Nozzle diameter & $1.2 \mathrm{~mm}$ \\
Jet angle & $90^{\circ}$ \\
Max. pressure & $400 \mathrm{MPa}$ \\
Max. flow rate & $520 \mathrm{~g} / \mathrm{min}$ \\
Stand-off distance & More than $1 \mathrm{~mm}$ \\
\hline
\end{tabular}

Experimental workpieces are $80 \times 50 \times 7.6 \mathrm{~mm}$ dimensions were machined under varying traverse speeds of $60,80,120,150,200$, and $250 \mathrm{~mm} / \mathrm{min}$ by AWJ machining.

After machining, the profiles of machined surfaces, and kerf geometries are measured. The measurements of upper and lower kerf widths were carried out using an optical microscope with an accuracy of $0.001 \mathrm{~mm}$. Three measurements of both kerf widths were performed and the arithmetic average recorded for all specimens.

MRR was calculated from the difference of weights of specimen before and after experiment. Weights were measured in laboratory using sensitive scale SCALTEC SBA 41 (Fig. 1).

$\mathrm{MRR}=\frac{W_{i}-W_{f}}{\rho t} \mathrm{~cm}^{3} / \mathrm{min}$

where $W_{i}$ is the initial weight of specimen in $g, W_{f}$ is the final weight of specimen after machining in $\mathrm{g}, \mathrm{t}$ is the machining time in min and $\rho$ is density of $\operatorname{Armox}\left(\mathrm{g} / \mathrm{cm}^{3}\right)$.

After cutting, the surface roughness of the machined surface was measured parallel to the feed direction using TR200 hand-held roughness tester (Fig. 2). Three values of surface roughness for each specimen were measured at the center of the produced surface, and an average value was calculated for each specimen. 


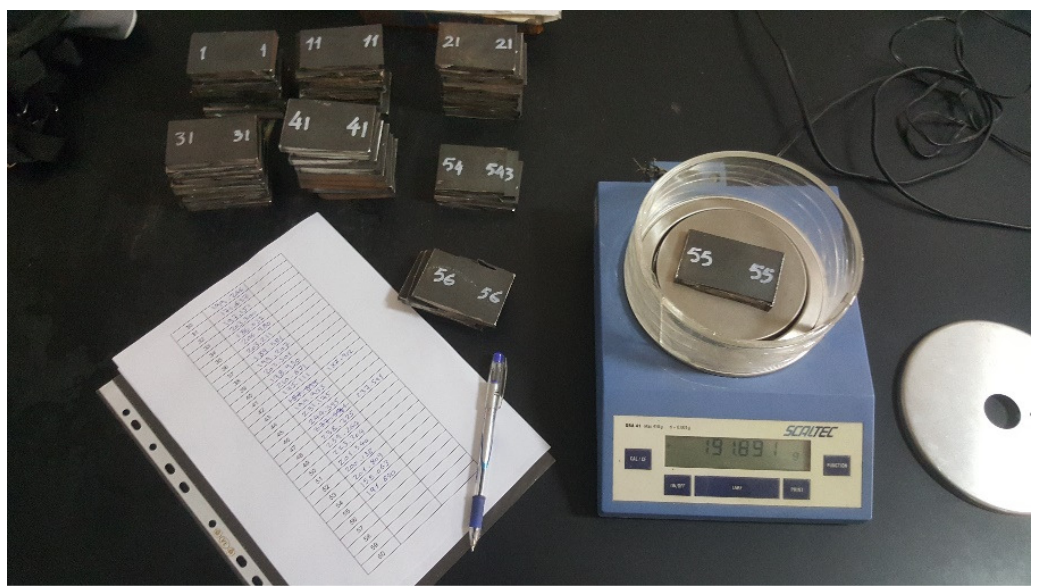

Fig. 1. Measuring weights of specimens in laboratory using SBA 41 sensitive scale.



Fig. 2. TR200 roughness tester apparatus.

\section{RESULTS AND DISCUSSION}

Results are arranged to describe the effects of cutting variables on cutting parameters. Therefore, the test results are categorized by cutting parameters. During the tests only one variable is considered at a time while the other variables are fixed.

\section{Surface Roughness}

Fig. 3 shows cutting surface view of sample machined surface. Microstructural evaluation of the cutting surfaces of samples revealed three distinct zones which were identified as [10]:

(1) Initial Damage Region (IDR), which is cutting zone at low angles of attack

(2) Smooth Cutting Region (SCR), which is cutting zone at large angles of attack

(3) Rough Cutting Region (RCR), which is the jet upward deflection zone [11]. 


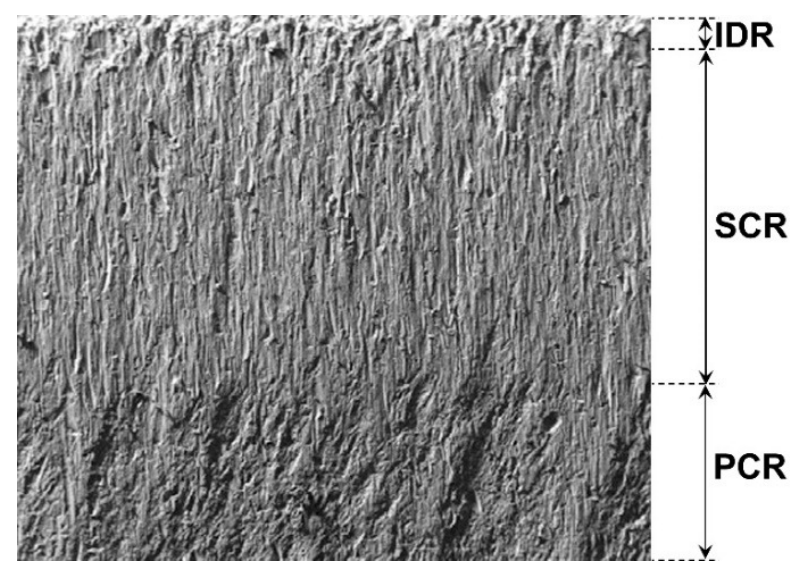

Fig. 3. Typical AWJ-machined surface regions [10].

The surface morphology in different regions of cutting surface is generated from the instantaneous penetration of abrasive waterjet. It is expected that these regions would change with an increasing interaction of the jet with the material, i.e., increased overlap at any region of cut.

The degree of plastic deformation increases from the top to the bottom of the cutting surfaces. In the IDR of the cutting surface, abrasive particles have a sufficient level of kinetic energy to destruct the material. This small damaged region is characterized by a small rounded corner at the top edge due to the plastic deformation of material caused by the initial AWJ bombardment. As the abrasive particles penetrate into the material, some of the energy is used in eroding the material in the SCR and the stream loses kinetic energy [10].

A jet with lower energy tends to deflect in the normal direction to the plane of cutting, which will result in striations to be formed on the cutting surface. As the abrasive jet stream traverses, the part, the stream is deflected, hence resulting in the creation of a unique cutting geometry. The degree of deflection increases with increasing traverse speed [12].

\section{Effect of traverse speed on surface roughness}

As the traverse speed increases, the number of particles impinging on a given exposed target area decreases, which in turn reduces the $R_{a}$ slightly. The surface roughness $\left(R_{a}\right)$ parameter values were measured at different travers speeds. As shown in Fig. $\mathbf{4}$ the increase of traverse speed, surface roughness increases.

\section{Effect of jet pressure on surface roughness}

The effect of jet pressure on surface roughness $R_{a}$ parameter was tested under ranges of pressures from 100 to $250 \mathrm{MPa}$. In general, an increase in the pressure improves the surface quality. These because the increased fragmentation probability of the abrasive particles with an increase in their velocity. This fragmentation reduces the size of the impacting abrasive particles. Also, an increase in the pump pressure increases the abrasive water jet kinetic energy. This process allows part of the excess energy to smoothen the surface. Fig. 5 shows the jet pressure does not have a significant influence on the roughness in the upper range of the cut. In this 


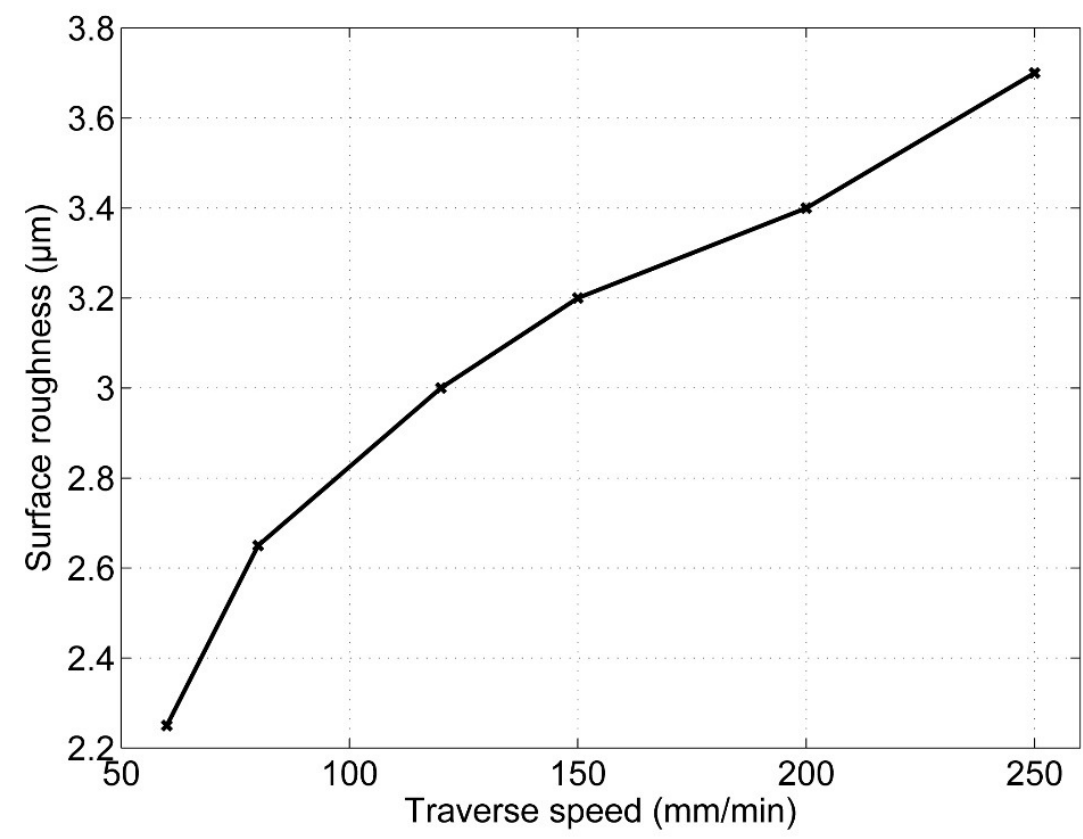

Fig. 4. Effect of traverse speed on surface roughness.

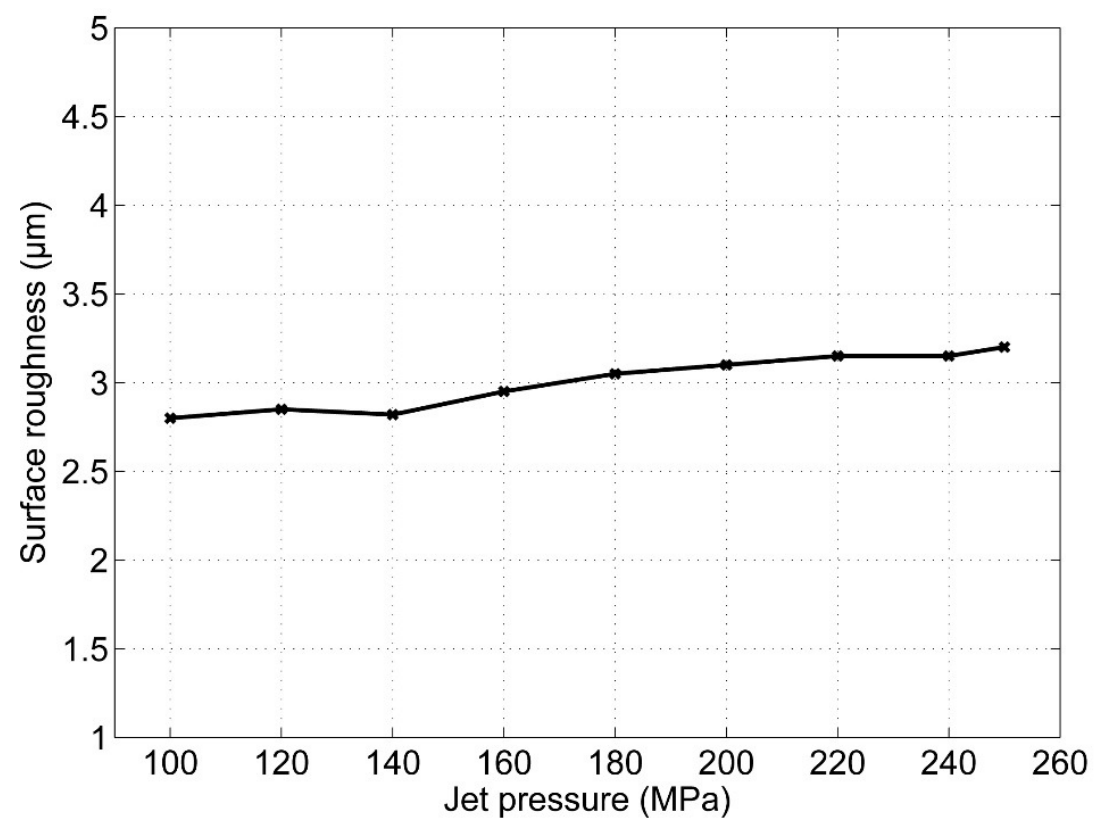

Fig. 5. Effect of jet pressure on surface roughness.

range it was found that when the jet pressure increased, the surface roughness $R_{a}$ had negligible value change Therefore; it is conducted that jet pressure has no major effect on surface roughness $R_{a}$ in the tested pressure range.

\section{Effect of abrasive flow rate on surface roughness}

Fig. 6 shows the influence of the abrasive flow rate $\left(m_{a}\right)$ on the surface roughness $R_{a}$. In this figure, the roughness decreases with an increase in the abrasive flow rate. A high number of abrasive particles involved in mixing increases the probability of particle collision that decreases the average diameter of the impacting particles. 


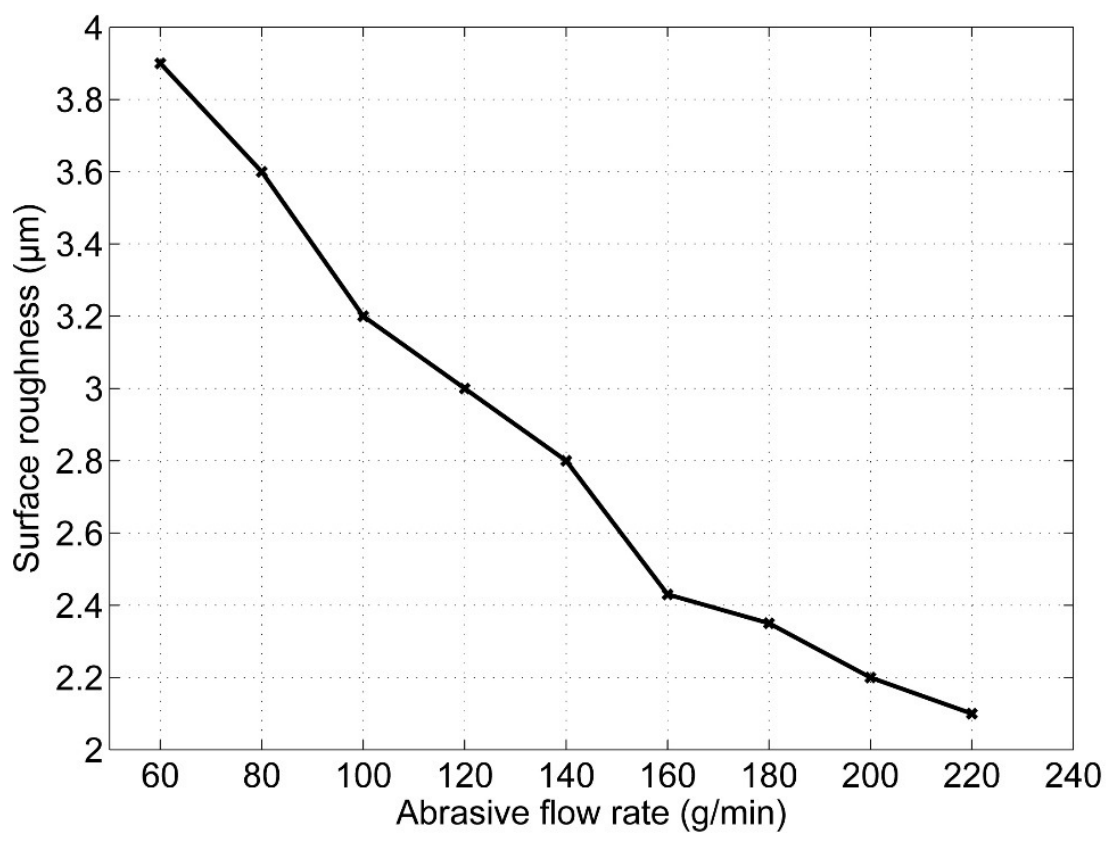

Fig. 6. Effect of abrasive flow rate on surface roughness.

\section{Effect of stand-off distance on surface roughness}

The effect of stand-off distance on surface roughness was tested. The test was conducted at four different values for stand-off distance. The results are illustrated in Fig. 7. The surface roughness $R_{a}$ values were changed with the increase of stand-off distance. Therefore; it is concluded that the stand-off distance has no effect on depth surface roughness in the tested range.

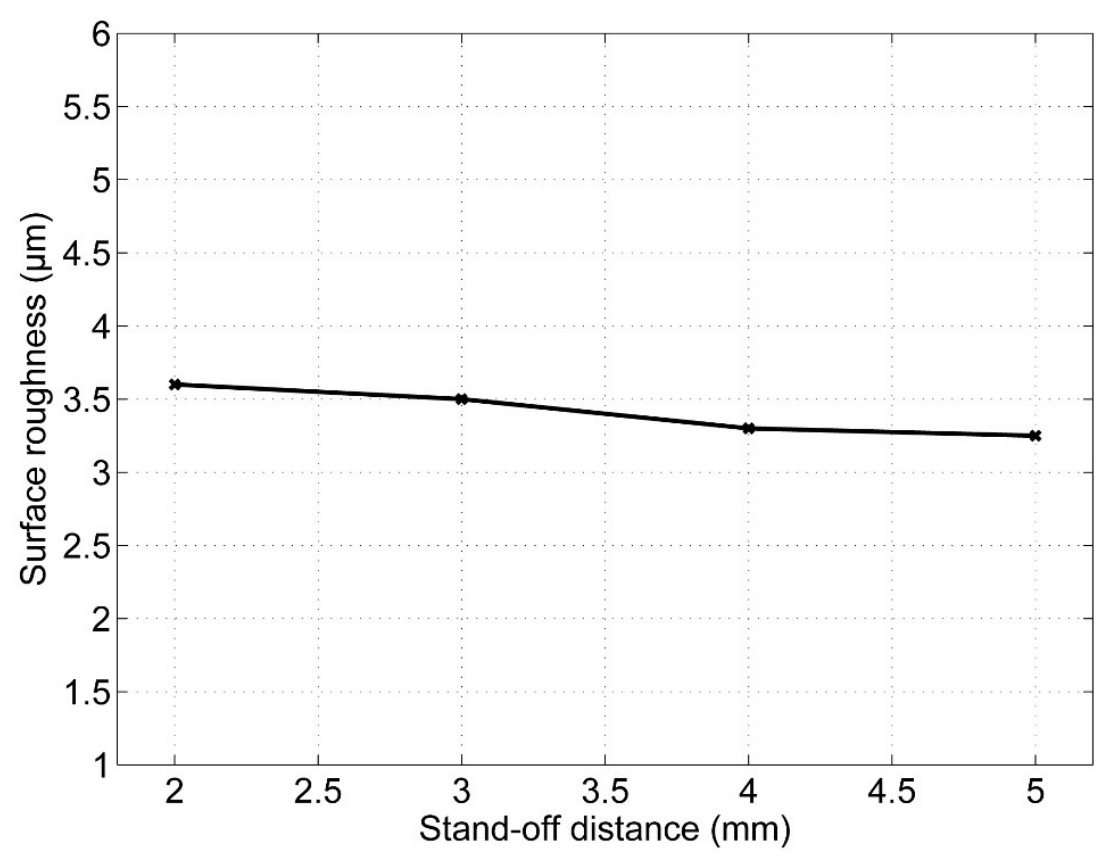

Fig. 7. Effect of stand-off distance on surface roughness. 


\section{Kerf geometry}

The kerf taper angle for each cut was calculated using the measured values of the top and bottom kerf width for each cut based on the equation [12].

$$
\theta=\arctan \left[\frac{\left(W_{t}-W_{b}\right)}{2 t}\right]
$$

Kerf geometry is a characteristic of major interest in abrasive waterjet process. The top kerf is commonly wider than the bottom due to the decrease in water pressure as a unique feature of AWJ technology. As a result of this, a taper is produced. The large kerf taper ratio worsens the perpendicularity or the straightness of the cutting cross-section, resulting in an inaccurate dimensional quality. A typical side view of the kerf is shown in Fig. 8. As traverse speed increases, top and bottom kerf widths decrease, but despite this, kerf wall slope increases slightly. This is because the traverse speed of abrasive waterjet allows fewer abrasives to strike on the jet target and hence generates a narrower slot.

As the traverse speed increases, the AWJ cuts narrower kerf widths with a greater kerf taper ratio, as shown in Fig. 9. Although the kerf taper ratio is differing for increasing traverse speed, this change is only $0.54^{\circ}$ for the tested specimens.

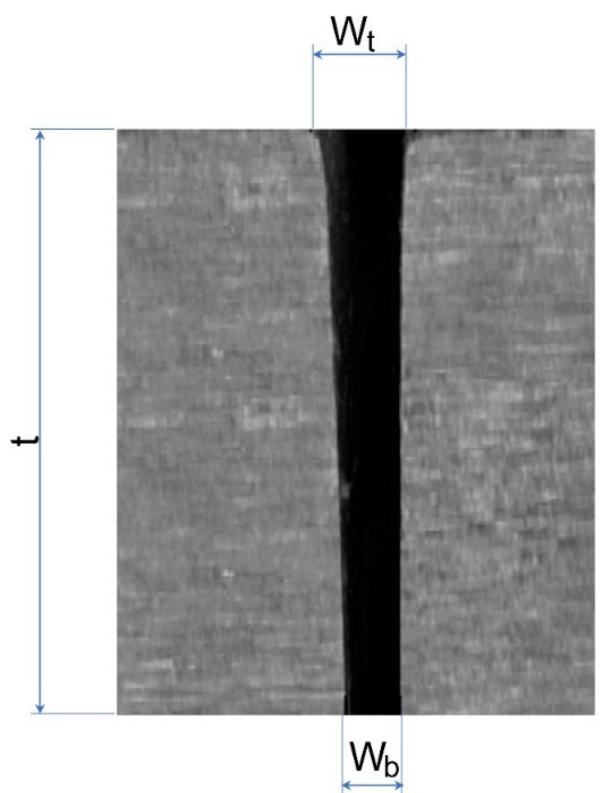

Fig. 8. A typical side view of the kerf [10].

\section{Material Removal Rate (MRR)}

The material removal rate is influenced mainly by the traverse speed, abrasive flow rate and size of abrasives. Larger grain sizes produce greater removal rates. At a particular pressure, the volumetric removal rate increases with the abrasive flow rate up to an optimum value and then decreases with any further increase in flow rate. This is due to the fact that the mass flow rate of the gas decreases with an increase in the abrasive flow rate and hence the mixing ratio increases causing a decrease in the removal rate because of the decreasing energy available for material removal [13]. 




Fig. 9. Effect of traverse speed on kerf taper ratio.

\section{Effect of traverse speed on MRR}

Fig. 10 shows the effect of variation of change in traverse speed on MRR. It shows that the increase of traverse speed increases the MRR in the range from 60 to 250 $\mathrm{mm} / \mathrm{min}$.

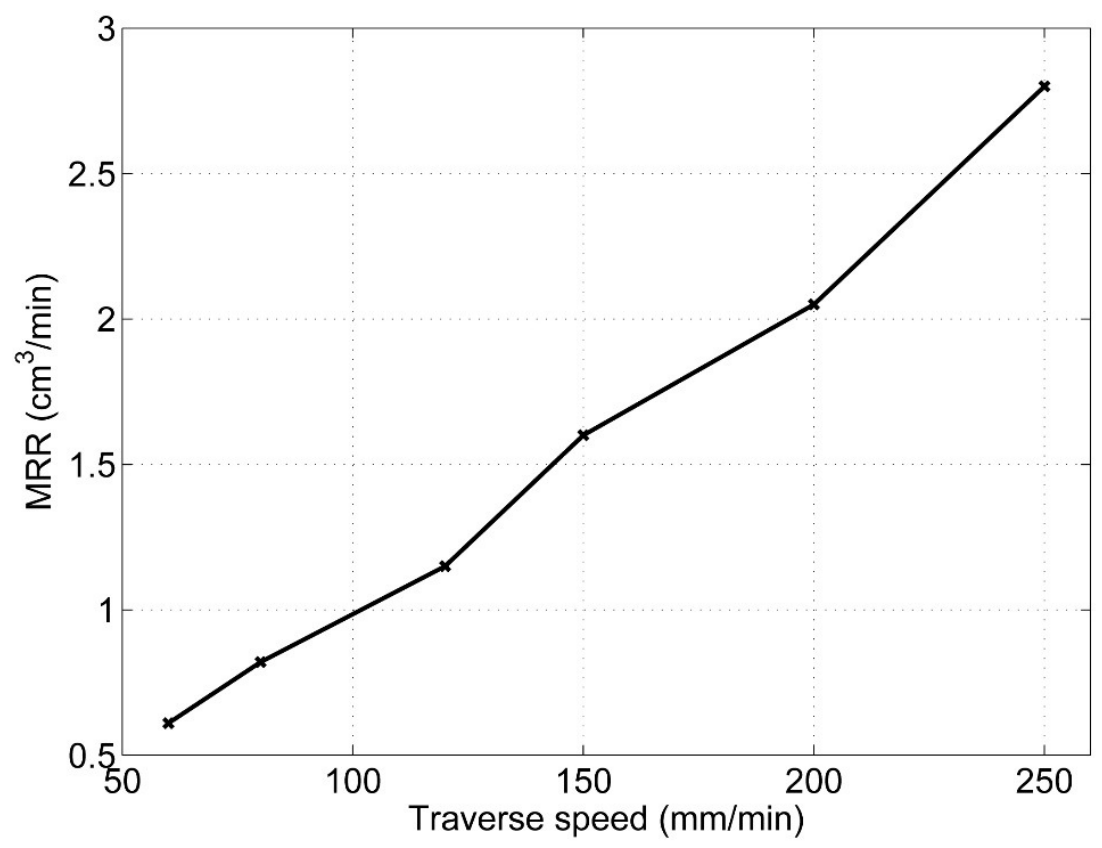

Fig. 10. Effect of traverse speed on MRR.

\section{Effect of jet pressure on MRR}

The effect of jet pressure on MRR was tested in range of jet pressures from 20 to $100 \mathrm{MPa}$. In this range, it was found that when the jet pressure increased the MRR 
was almost of a constant value. Fig. 11 shows the test results of the effect of jet pressure on the MRR.

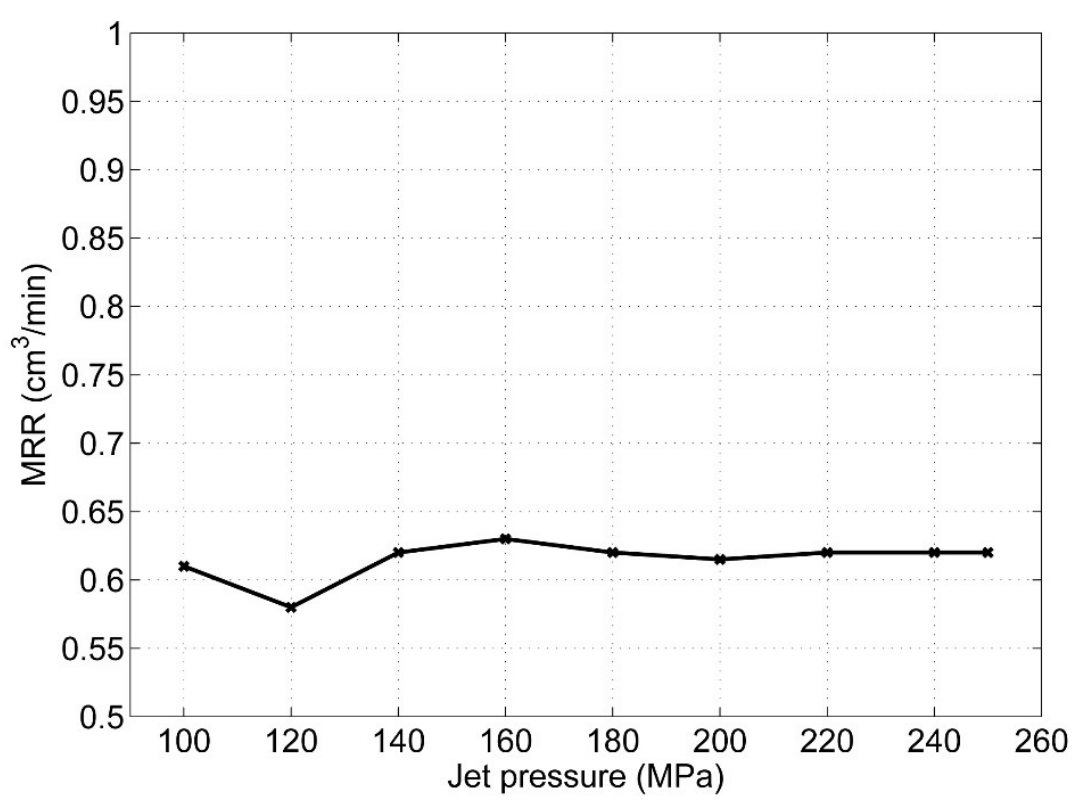

Fig. 11. Effect of jet pressure on MRR.

\section{Effect of abrasive flow rate on MRR}

A number of experiments were carried out to find the relation between the abrasive flow rate and MRR. During these tests the abrasive flow rate varied from 60 to 220 $\mathrm{g} / \mathrm{min}$. Fig. 12 shows the effect of abrasive flow rate variation on MRR.

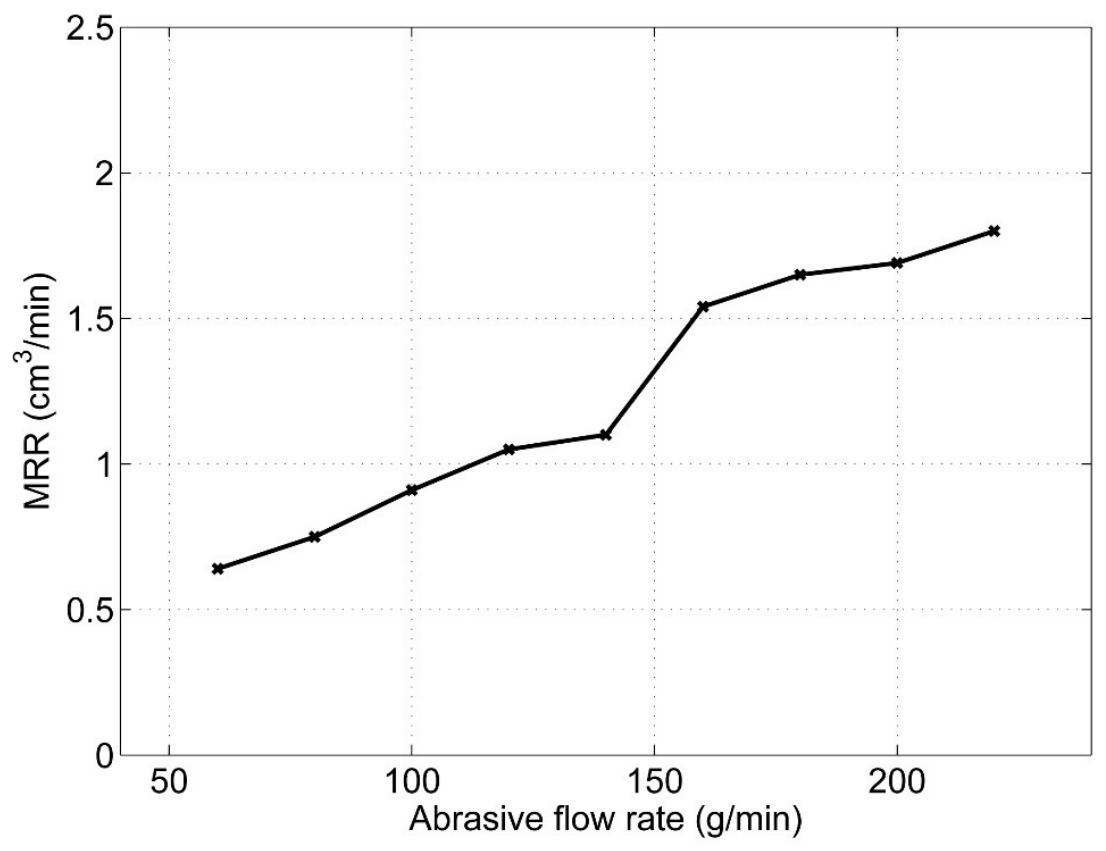

Fig. 12. Effect of abrasive flow rate on MRR. 


\section{Effect of stand-off distance on MRR}

The stand-off distance was changed and MRR measured. Fig. 13 shows that the stand-off distance has no significant effect on MRR value.

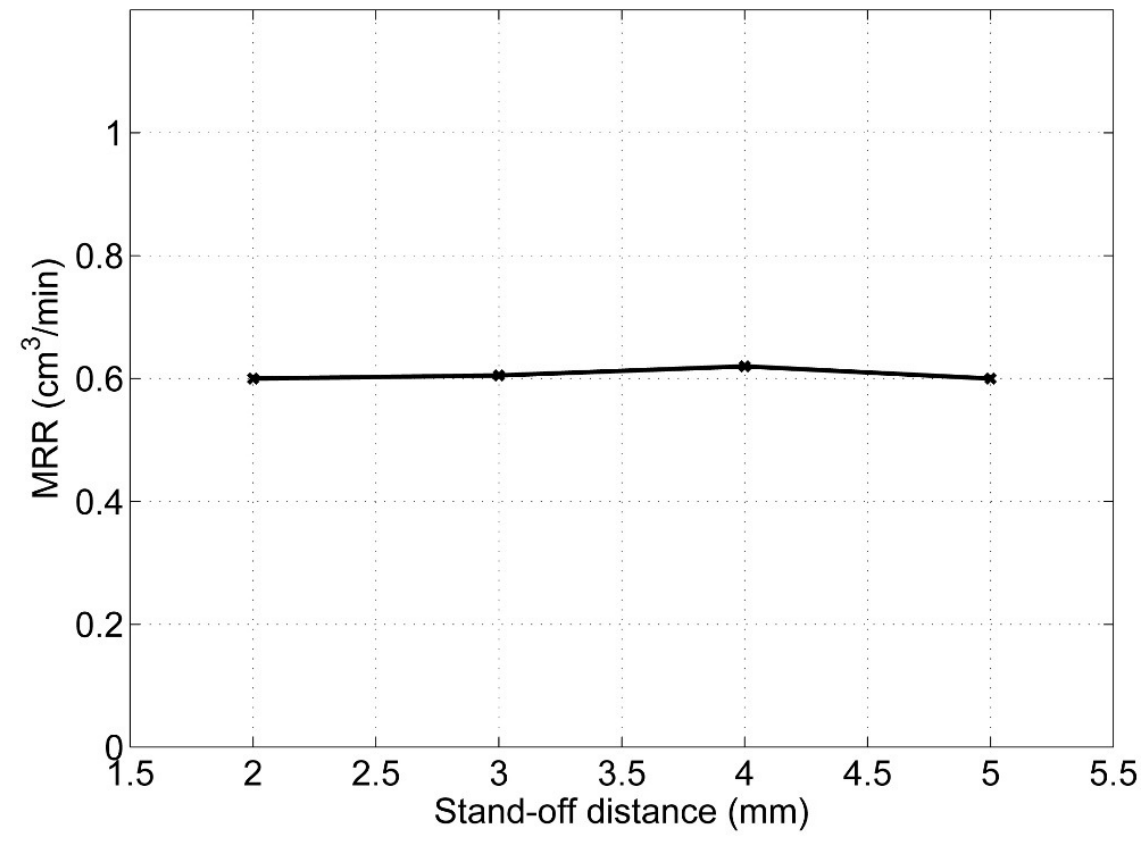

Fig. 13. Effect of stand-off distance on MRR.

\section{CONCLUSIONS}

In this study, the profiles of machined surfaces, kerf geometries, and material removal rate are investigated in terms of traverse speed, jet pressure, abrasive flow rate, and stand-off distance in AWJ machined Armox were investigated experimentally. Summarizing the main features of the results, the following conclusions are:

1) As the traverse speed increases, the quality of machined surface decreases.

2) The jet pressure of AWJ has no significant effect on the surface roughness.

3) As the abrasive flow rate increases, the quality of machined surface increases.

4) Stand-off distance has no significant effect on the surface roughness.

5) As the traverse speed increases, the AWJ cuts narrower kerf widths with a greater kerf taper ratio.

6) As the traverse speed increases, the MRR increases.

7) Jet pressure of AWJ has no significant effect on MRR.

8) As the abrasive flow rate increases, MRR increases.

9) Stand-off distance has no significant effect on MRR. 


\section{REFERENCES}

[1] Barényi, I., Lipták, P. and Vojtovič, S., 2014. Effect of over Tempering at UHSLA Steel ARMOX 500. In Advanced Materials Research (Vol. 875, pp. 1324-1328). Trans Tech Publications.

[2] Iqbal, M.A., Senthil, K., Sharma, P. and Gupta, N.K., 2016. An investigation of the constitutive behavior of Armox 500T steel and armor piercing incendiary projectile material. International Journal of Impact Engineering, 96, pp.146164.

[3] Romek, D., Ulbrich, D., Selech, J., Włodarczyk, K. and Kowalczyk, J., 2017. Evaluation of wear of machine parts made of Armox 600, Ramor 500 and S355 steel with the use of the rotating bowl unit. Journal of Research and Applications in Agricultural Engineering, 62(2).

[4] Hashish, M., 1984. A modeling study of metal cutting with abrasive waterjets. Journal of Engineering Materials and Technology, 106(1), pp.88-100.

[5] Arola, D. and Ramulu, M., 1993, August. Mechanism of material removal in abrasive waterjet machining of common aerospace materials. In Proceedings of the 7th American Water Jet Conference (pp. 43-64).

[6] Hashish, M., 1991. Optimization factors in abrasive waterjet machining. Journal of Engineering for Industry, 113(1), pp.29-37.

[7] Blickwedel, H., Guo, N.S., Haferkamp, H. and Louis, H., 1990, October. Prediction of abrasive jet cutting performance and quality. In Proceedings of 9th International Symposium on Jet Cutting Technology (pp. 163-179).

[8] https://www.ssab.com/products/brands/armox

[9] http://www.soitaab.com/index_en.php

[10] Hascalik, A., Çaydaş, U. and Gürün, H., 2007. Effect of traverse speed on abrasive waterjet machining of Ti-6Al-4V alloy. Materials \& Design, 28(6), pp.1953-1957

[11] Wang, J., 1999. Abrasive waterjet machining of polymer matrix compositescutting performance, erosive process and predictive models. The International Journal of Advanced Manufacturing Technology, 15(10), pp.757-768.

[12] Momber, A.W. and Kovacevic, R., 2012. Principles of abrasive water jet machining. Springer Science \& Business Media

[13] El-Hofy, H., 2005. Advanced machining processes: nontraditional and hybrid machining processes. McGraw Hill Professional. 